\title{
A Socio Semiotic Approach to Multimodal Discourse of Selected Nollywood Film Advertisement Posters
}

\author{
Monsurat Aramide Nurudeen 1, * [ahmedmonsurat66@yahoo.com +2349036550052] \\ Ebenezer Oluseun Ogungbe ${ }^{2}$

\section{Moshood Zakariyah ${ }^{3}$} \\ ${ }^{1}$ Department of English, University of Ilorin, Ilorin. P.M.B. 1515: Ilorin, Nigeria \\ ${ }^{2}$ Department of English, IBB University, Lapai, Nigeria \\ ${ }^{3}$ Department of English, Kwara State University, Malete, Nigeria.
}

Received: 28.09.2021 • • Accepted: 23.12.2021 • Published: 31.12.2021

\begin{abstract}
Film posters are complex forms of visual communication basically employed to promote films so as to seek for patronage from prospective viewers. Nollywood film poster designers or marketers employ a complex system of modes of multimodal communication to achieve their intended objectives. This study therefore investigates how these semiotic resources reveal the intention of the film poster designers and how other contextual variables influence the ability of the viewers to comprehend the messages embedded in film posters. The objectives of the study are to uncover the visual and linguistic semiotic resources in the film advertisement posters and their interaction. The study adopts a qualitative approach to the analyses of six randomly selected Nollywood film advertisement posters of three genres, namely: drama, thriller and comedy. Yuen's Generic Structure Potential and Royce's Ideational Intersemiotic Complementarity serve as the basis for the analysis of the selected texts. The study reveals that visual modes are more salient and frequently employed in the advertisement posters than the linguistic modes. However, both the visual and the linguistic modes offer complementary relationship for effective meaning-making in the selected Nollywood advertisement posters. The meanings derived are often contextual which appeal to the audience reasoning and sustain their interests. The study concludes by emphasizing the importance of the synergy of both linguistic and visual multimodal resources or modes of signification in the successful meaning-making and meaning-comprehension in the study of visual communication.
\end{abstract}

Keywords: Nollywood; film posters; socio semiotics; generic structure

\section{Introduction}

Nollywood or Nigerian film industry has provided an opportunity for the world to see and appreciate the socio-cultural values and experiences of Nigerians. Nigerian films are veritable means for socializing, informing, educating and also empowering the human resources of Nigeria.The intention of Nigerian movie producers, which are didactic and informative in nature, is expressed via Nigerian indigenous languages, Nigerian Pidgin and Nigerian English.

The popularity of Nollywood films can be traced to the new cinema culture in the country which is a paradigm shift from the traditional cinema that features live presentation to the production of recorded films in a new theatre. Nollywood films are broadcast in cinemas nationwide and are

\footnotetext{
*Corresponding Author: ahmedmonsurat66@yahoo.com
} 
available online for download by prospective subscribers. A prominent station that serves as a platform to showcase Nollywood films internationally is African Magic DSTV/GOTV, where there are several channels tagged under different names such as African magic Yoruba, showcase, Epic, Igbo, Hausa and many more so as to reach out to different audience particularly in terms of religion and ethnicity. In addition to YouTube, a new online platform called NETFLIX has emerged which features Nollywood for the consumption of local and international subscribers.

A major tool used by film producers to increase the patronage of their films is film publicity, which plays a central role in the movie production process. Essentially, Nollywood films are produced from time to time. Hence, in order to sustain themselves in the rather flooded and competitive market, Nollywood film producers and marketers use different publicity techniques. One of these publicity techniques employed in achieving their desired objectives is the poster print medium. Anyawu (2015, p.130) expresses that "Nollywood film posters are subsumed under the print media which are the strongest outlets of movie publicity in Nigeria. They are considered highly effective because they usually get their message across to the target audience."

Nollywood film poster designers employ a plethora of semiotic resources on film posters which are often reflectors of Nigerian socio-cultural context. There is a need to interpret these highly context-based semiotic modes employed in getting the attention of the viewers. Thus, this study aims to uncover how these semiotic resources reveal the intention of the film posters' designers and how other contextual variables influence the ability to comprehend the messages intended. This research is a different from other previous studies, which focus only on the visual resources of film posters or its aesthetic design as it investigates how various modalities and semiotic tools are organized and presented concurrently to create meaning. This study aims to bridge these gaps by applying multimodal discourse analysis (MDA) to selected Nollywood film advertisement posters with the following objectives:

1. to identify and interpret visual and linguistic semiotic resources in the film advertisement posters;

2. to examine the interaction between visual and linguistic semiotic resources in the film advertisement posters; and

3. To unravel the influence of social context in the encoding and decoding of meaning in the film advertisement posters.

\section{Theoretical Background}

\subsection{Multimodal Discourse Analysis: A Theoretical Overview}

The ubiquitousness of meaning making is not limited to a single mode of communication. The field of discourse analysis has been deficient in this respect. Hence, the need for a viable field of study to account for the complexities in human interaction is what multimodality or multimodal discourse analysis addresses. The tenancy of this field of study as opposed to the traditional single focus of discourse studies have been argued by different scholars.

Oyebode and Olateju (2014) submit that the need for discourse analysis to incorporate the variable relationship of text structure to text function, as well as visual skills is the gap multimodal discourse analysis now fills. Similarly, Ron and Phillips (2004) comment that discourse is inherently multimodal in nature and not monomodal, because the issue of opening up the lens to discover a fuller view of how humans communicate in modern world is essential in discourse study. In the same vein, Lemke (1995, p.7) posits that "multimodal factors exists within the language itself and that they do not come only as additional elements. He contends that discourse in general is an aspect of 
social action; it never makes meaning with language alone'. In tandem with the above assertion, Kress, Leite-Garcia \& van Leeuwen (1997, p.256) maintain that:

...the change in producing texts which are strongly multimodal. That is, producers of texts are making greater and more deliberate use of a range of sensational and communicational modes, which co-occur with one text. One effect of this change is that it has become impossible to read texts reliably by paying attention to written language alone: it exists as one representational element in a text which is multi-modal, and it has to be read in conjunction with the other semiotic modes of the texts.

Machin (2007, as cited in Liu 2013) posits that multimodality explains the grammar of visual communication that is used by image designers. It is the analysis of the rules and principles that allow viewers to comprehend the meaning potential of relative placement of elements, framing, salience, proximity, color saturations, styles of typeface, etc.

From the foregoing, the concept of multimodality is, indeed, a useful yardstick to measure and evaluate the diverse ways of meaning making. According to van Leeuwen and Jewitt (2001), there are a number of ways to do MDA such as social semiotic analysis, conversation analysis, and content analysis and so on. These multimodal dimensions have their peculiarities that are socially grounded and conventionally guided.

\subsection{Social Semiotic Approach to Multimodal Discourse Analysis}

The theoretical foundation of social semiotic approach to multimodal discourse analysis is derived from Systemic Functional Linguistics (SFL) view of language as a social semiotic or social phenomenon (Halliday 1978, 1985). Halliday (1978) states "that semiotics is a process of making meanings by selecting from the total set of options that constitute what can be meant." Therefore, O'Halloran (2008, p. 444) postulates that "the systemic functional approach or social semiotic to multimodal discourse analysis is concerned with the theory and practice of analysing meaning arising from the use of multiple semiotic resources from discourses which ranges from written, printed and electronic texts to material lived-in reality."

O'Toole (1994) and Kress and van Leeuwen $(1996,2006)$ laid the foundation for MDA from the systemic functional perspective. More scholars have since used the theoretical principles of SF theory to the analysis of other semiotic systems other than language and or their interrelationship to name a few are: Royce (1998), Yuen (2004), Martinec (1996), Lim (2004), Van Leeuwen (1999,) among others.

\section{Theoretical Orientation}

The study employs Yuen's (2004) generic structure of printed advertisements and Royce's (1998) intersemiotic complementarity as theoretical underpinnings for the analysis of the data because of their ability to unravel the meanings communicated via the visual and linguistic semiotic resources embedded in the advertisement posters and their interrelationship. These two theories are also social semiotic perspectives to multimodal discourse analysis and have strong roots in systemic functional linguistics. 
The Generic structure potential accounts for the multi-semiotic interaction between visual images and linguistic text in print advertisements. The theory hinges on Hasan's (1996) insufficiency on the generic structure for an advertisement. Yuen (2004, p.176) argues that "Hasan (1996) establishes 'Capture ${ }^{\wedge}$ Focus $^{\wedge}$ Justification' as the generic structure for advertisements but my research has produced a GSP which differs in terms of the degree of detail and the ability to capture the complexity of intersemiosis in advertisements". The GSP is classified into two components: the visual and the linguistic (semiotic resources working together in projecting meaning). The visual components consist of the Lead, the Display and the Emblem while the linguistic entails Announcement Enhancer, Emblem, Tag and Call-and-visit information. With this system, print advertisement is considered as a single united commodity that is analyzed by deconstructing its elements.

The Lead is the most salient image because it is the focus of attention that attracts the viewers to the advertisement. It consists of lesser elements termed as the Locus of Attention (LoA), which is the most salient item or items in the Lead; and the Complementary Locus of Attention (Comp.LoA), that is, the background or other visuals, which are less salient than the LoA but complementing the LoA. The second element, the Display, demonstrates the characteristics of the Lead, which may be Explicit/Implicit and Congruent/Incongruent. An explicit lead explains if the picture is about a tangible object while an implicit lead details if the intangible product or service is given tangible form through another medium. In addition, the Lead is called Congruent if the product is not realised through symbolism and incongruent if the product is realised through symbolism. The third element in the visual image component is the Emblem, which is usually the company's logo.

The second aspect of GSP is the linguistic aspect, which is interpreted by several elements such as: Emblem, Announcement, Enhancer, Tag, and Call-and-Visit Information. Emblem in the linguistic component comprises the linguistic slogan, which may accompany the visual Emblem, (the company's logo). Announcement is the most salient linguistic text in the advertisement; and based on the level of salience, Announcement consists of both the primary and Secondary Announcements, which are deployed to capture the readers' attention of the advertised product. Furthermore, Enhancer is the part of the advertisement that explains further the Announcement, and it is usually in smaller fonts and in the form of a paragraph. Tag is the additional phrase or clause to further complement the visual. Lastly, Call-and-Visit Information is usually evident and depicted in small prints that are non-salient and contain contact information as to where, how and when the products and services are available to consumers. This representation is thus captured by Yuen (2004, p.163) as:

Lead $^{\wedge}(\text { Display })^{\wedge}$ Emblem $^{\wedge}(\text { Announcement })^{\wedge}(\text { Enhancer })^{\wedge}(\text { Tag })^{\wedge}($ Call-and-Visit Information $)$

Yuen (2004) adopts Halliday and Hasan's (1989) notations for generic structure in texts by making use of the symbols above to express the total range of obligatory and optional elements, where the caret sign"^" means "followed by" and the round brackets () means that the elements inside them are optional. She maintains that the obligatory elements that always occur in print advertisement are the lead and the emblem, while others are optional.

The centrality of Intersemiotic Complementarity is how visual and verbal modes co-occur in multimodal texts to complement each other semantically to produce a single textual phenomenon, which can be realized through ideational, interpersonal and textual meanings (Royce 1998, p.26). The ideational intersemiotic meaning is the focus for this study, and it is actualized when both linguistic and visual modes are related lexico-semantically through intersemiotic sense relations: repetition- identical experiential meaning, synonymy- same or similar experiential meaning, 
antonymy- opposite experiential meaning, hyponymy- the relationship between a general class of something and its sub class, Meronymy -the relationship between part and whole, and collocationexpectancy or high probability to co-occur in a field or subject area.

This study, therefore, investigates how communicative and persuasive goals are achieved in Nollywood film advertisement posters through the engagement of these two theories as tools for unpacking the meanings in the advertisements.

\section{Methodology}

The data for the study is qualitative in nature. Thus, six randomly selected Nollywood movie posters are used in the study. The selected posters are of three different genres. They are comedy, thriller and drama themed films. The classification of the film posters into these genres were based on the synopsis of the films advertised. Ertugrul and Karagoz (2018, p.248) note, "Movie plot summaries reflect the genre of the movie ... such that people can easily capture the genre information of the movies from their plot summary". Two of each of these genres was selected for analysis making a total of six posters. The study is not aimed at conducting a comparative study of the genres of these movie posters but rather, to explicate the general features of the multimodes employed in the data.

The choice of the film posters selected is premised on the fact that they describe the thematic preoccupation and or/synopsis of the films concerned. Similarly, the film posters replicate the audience socio- cultural experiences and contextual nuances. The advertisement posters are also flourished with visual and linguistic semiotic resources, which authenticate the theoretical models employed in the study. The posters were retrieved from various internet sources. Subsequently, the study applies Yeun's Generic Structure Potential and Royce's Ideational Intersemiotic Complementarity to the analysis of the data. The selected poster figures are labeled from 1 to 6 and a short introduction is given to each one.

\section{Data Analysis and Discussion}

Generic Structure Potential of the Advertisement Posters

Poster 1

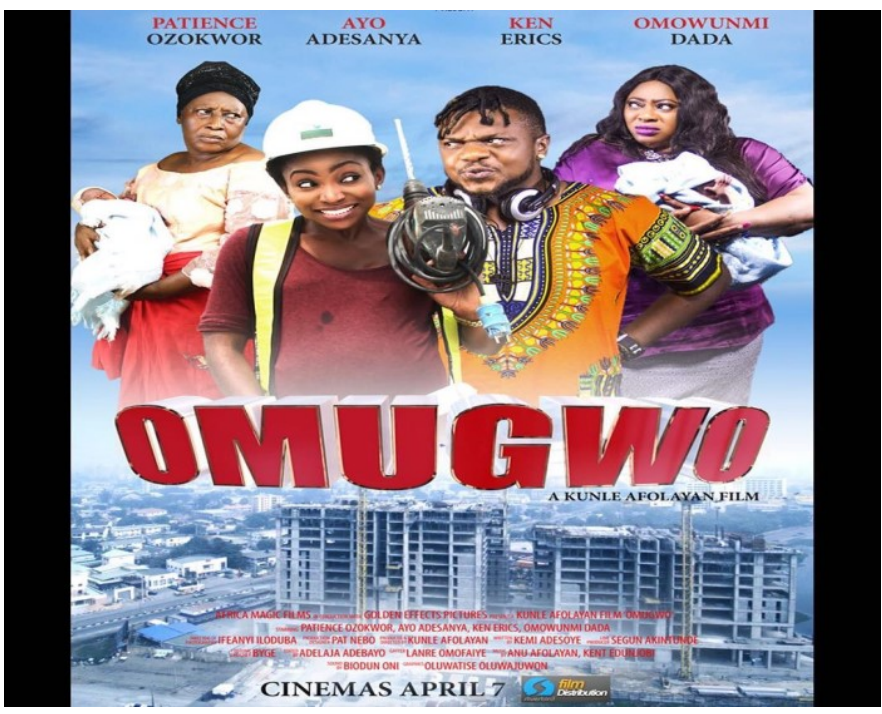


Figure 1. Omugwo film poster

Figure one above is a comedy movie produced in 2017 by Kunle Afolayan. The poster contains a lead that is divided into the locus of attention (LoA) and the complement of the locus of attention (Comp. LoA). The LoA is the image of four represented participants, consisting of two women holding babies wrapped in a shawl and a young man and woman who appear to be a couple. The gazes of the women at the background are directed at each other and show disdain, which is a strong indication that they are at loggerheads with each another. This non-verbal act arouses viewers' curiosity since, their facial expressions contrast with the couple in the foreground. The cosmic setting below the image of the leads displays gigantic skyscraper buildings, stream of corrugated roofs suggesting urban life, which work in complementarity as Comp.LoA.

The semiotic resource of dress plays a significant role in informing the viewers about the occupation of the leads at the foreground that they are an engineer and an on air personality (OAP). Similarly, the clothing of the elderly female leads on both ends is dissimilar: while one is dressed in traditional Igbo attire to reinforce the film title, the other is dressed in more fashionable contemporary outfit. This lack of similarity in the dressing of the leads is symbolic of culture clash in the film narrative.

The image is awarded more explicit details by the implicit and incongruent display of the women and babies held in the hands of the supposedly grandparents, depicting the thematic focus of the film, 'Omugwo'. The title is semantically foregrounded with Nigerian Igbo culture. The lexical word 'Omugwo' refers to the Igbo traditional after birth care, which involves the nursing mother and her baby being taken care of by the mother of the nursing mother and / or mother- in- law or another close relative. Hence, the babies are symbols that connote the 'Omugwo' care by grandparents depicted in the background. The poster appeals to the sensibilities of Nigerian Igbo viewers as well as other non-Igbo viewers who share diverse cultural values.

Red is predominantly used to stir the emotion of the viewing audience. It also connotes disagreement between the women at the background. The red hue is apparent in the PA / title, first names of the cast, Patience Ozokwor's wrapper, the enhancer that is, the cast and crew imprinted at the bottom of the poster and the linguistic and visual emblems.

Poster 2

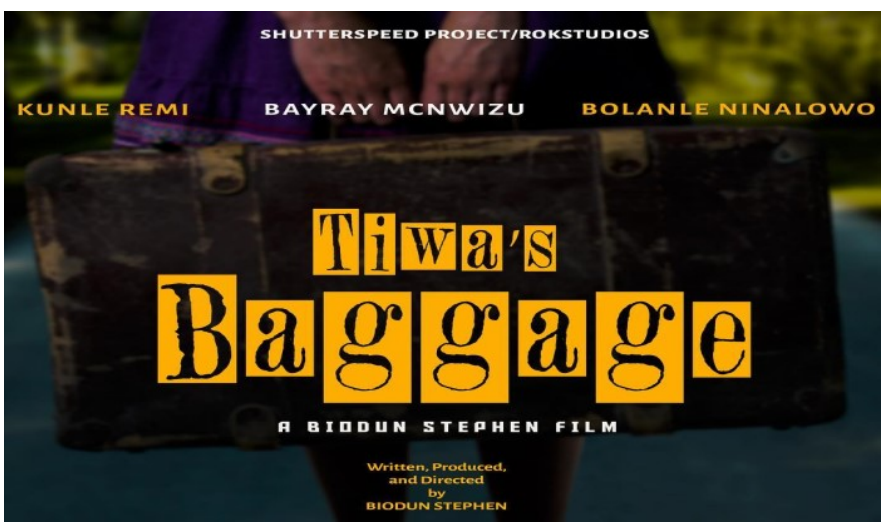

Figure 2. Tiwa's Baggage film poster

Figure 2 above is a drama movie produced in 2017 by Biodun Stephen. The leads in the poster are the image of a female hands and the tattered baggage held in the hands. The image of the baggage is made salient to create a strong visual effect on the viewers. The legs of the lead are also made 
salient to enhance visual meaning and they are the confluence of attention. The central idea or linguistic equivalence in embedded in the PA. These semiotic resources cohere ideationally to convey an intended message to the audience. Essentially, the lead is "figuratively an effervescence of meaning" (Yuen 2004, p.178). The meaning communicated through them could be interpreted in two ways or have two meaning potentials. In other words, the meaning could be physical denotative meaning of the semantic scope of the film plot, about a lady's (Tiwa) baggage or it could convey metaphorical sense, that is, the old and tattered baggage held by the visual lead, might be a visual metaphor implying that there are negative experiences from her past that endanger her present and probably her future. The salience of the image of the baggage may possibly imply the abundance or weight of these negative experiences. The intended meaning of the visual composition will be made available to viewers when they see the movie.

Furthermore, the linguistic element of the secondary announcement supports the PA in informing the audience that the film is owned by the popular Biodun Stephen. The information is reiterated and explained further in the enhancement at the bottom of the poster that the movie was produced, directed and written by her. The tags constitute the cast at the top of the poster while the linguistic emblem encapsulating 'shutter speed project/ Rok studios' further bestows the identity of the film advertisement and validates it.

The analysis of colour in the poster reveals that yellow is generously employed in the poster especially in the textual elements. It also illuminates the greenery of the background in which the leads are foregrounded. Yellow is associated with freshness and happiness. It brings optimism to the negativity or pitiable experiences the baggage carrier may undergo. It informs viewers that the film will have a happy ending. In addition, the purple colour of Tiwa's skirt or gown symbolizes mystery. Due to the partial representation of her on the poster, viewers are unable to observe every detail about her. Purple also signifies mystery to the thematic focus of the film, which is derived from the different interpretations arising from it.

\section{Poster 3}

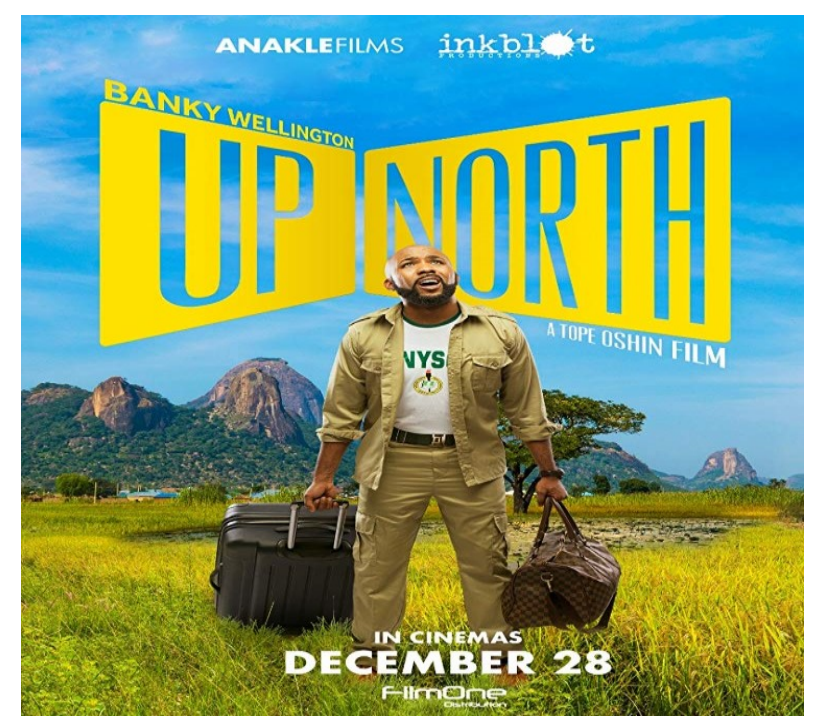

Figure 3. Up North, film poster

'Up North' is a drama movie produced in 2018 by Isioma Osaje, Zulumoke Onuekwusi and Editi Effiong. Figure 3 above consists of the visual lead, which is the most salient visual resources in the image referred to as the LoA. The LoA is depicted by the full image of a man standing in upright 
position looking up in awe. Held in his hands, are travelling luggage or (Comp.LoA). His representation creates a sense of curiosity to viewers and arouses their visual attention as they seek to know the reason for his facial expression which suggests that he is overwhelmed and distressed about the thought of going 'up North'. His gaze also visually reiterates the meaning conveyed by the preposition 'up'. The LoA is also cloaked in National Youth Service Scheme (NYSC) uniform. The NYSC is a compulsory one year scheme for qualified Nigerians who are graduates of tertiary institutions both home and abroad. The multimodal resources of this dress code in relation to the PA or movie title has been able to lend further information to viewers that the lead is a member of NYSC posted to the North. The implication of this dressing also reaches out to the situational context of Nigeria particularly, its youths. Thus, gearing them to associate with the LoA and see the movie.

The complement of the locus of attention / Comp. LoA also constitutes the background in which the lead is foregrounded. It shows how realistic the image is and enables viewers to have a view of the movie narrative that the film is about a corps member posted to the Northern part of the country. His luggage implies that he has just arrived or about embarking on his journey. It also relates with the landscape as well as the arrow facing the North in which the title of the film is imprinted to signal the thematic preoccupation of the film, that is, the verbal text, 'Up North'.

Since "colour is multifunctional in its uses in the culturally located making of signs" (Kress and van Leeuwen 2002, p.343), the yellow hue preponderantly used in the poster blends with the scenery and bright reflection on the face of the lead to connote the sunny Northern region of Nigeria. The lettering of The PA /'Up North' and the SA / 'Banky Wellington', are also in yellow colour to project them as related verbal entities.

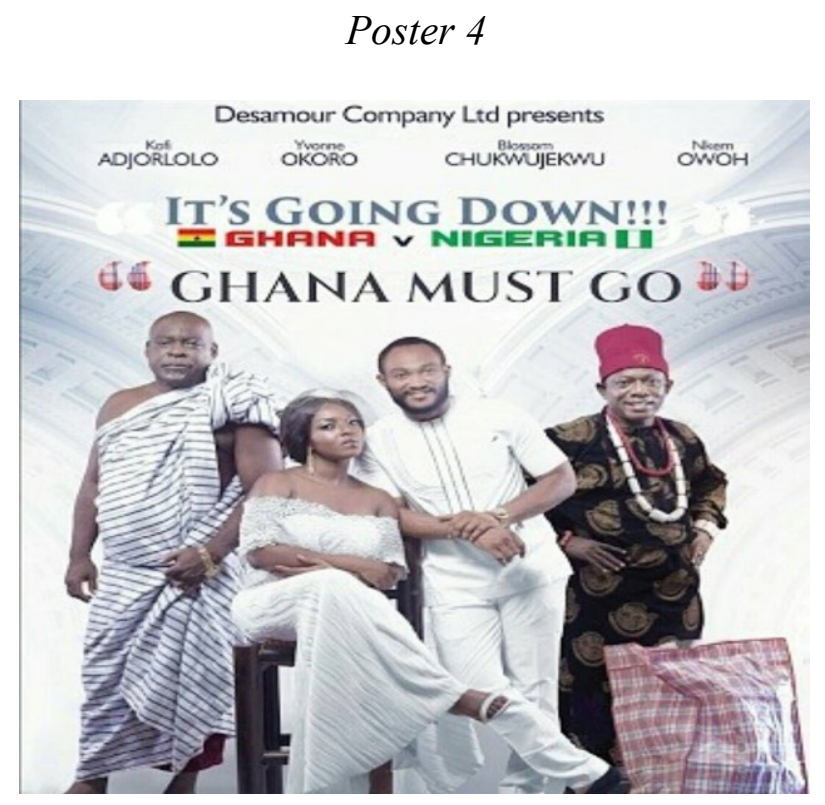

Figure 4. Ghana must go film poster

'Ghana must go' is a comedy movie produced in 2016 by Yvonne Okoro. The poster portrays the visual leads, which are the images of four represented participants; three males and one female. The female lead sits beside the young man that can be seen resting his arms on the chair head rest. They appear to be a couple. Foregrounded at both ends of the couple, are the image of two elderly men. They are dressed in native attires peculiar to Ghanaian and Nigerian Igbo tribes respectively. These apparels connotes that they are citizens of these countries. The complement of the locus of 
attention/ decontextualized background buttresses the meaning conveyed in the poster. The background is in grey and white colours. Grey create a framing that segments the leads into two parts which correlate with the tags/verbal texts; 'Ghana' v 'Nigeria' and their respective flags. Thus, viewers can discern that the elderly lead in Ghanaian native attire and the young woman beside him are Ghanaians and may be involved in a father/daughter relationship. The same role applies to the Nigerian counterparts; father and son. The leads gaze directly at the viewers. This is to involve viewers in active participation with them and the advertisement. The facial expression of the Ghanaian leads is stern as though they are not happy about something. However, the Nigerian leads wear a smiling look. Their facial expression are inviting as though they are on the winning team.

The display of the lead is congruent because the visualized 'Ghana must go bag' echoes the movie title/PA. These visual/verbal complementary semiotic resources are symbolic of the historical relation between Ghana and Nigeria. As the sack bag has become a household name, which serves as a symbol of exclusion and intolerance. A careful study of the poster shows that there is a culture clash between these two teams. The Ghanaian team is likely to be in Nigeria, hence, the film title. It is, thus, eminent that history is about to be repeated; migration of Ghanaians from Nigeria, which posits a culture clash that affects the couple's love life.

The linguistic resources of the PA/ 'Ghana must go', SA / 'it's going down' and tags / 'Ghana v Nigeria', interestingly create an analogy with an actual football match. Viewers are left to ponder if it is a physical fight between the two parties, the reason for the disarray and other events that took place in the movie narrative. However, the exclamation mark after the PA emphasizes that there is indeed a conflict between the two parties. Also, the tags/ 'Ghana v Nigeria' lends credence to the two teams. Similarly, the images of the flags beside them are symbols of both countries as nations. They exhibit patriotic undertone. Other tag information or names of the cast provide further identity of the images of the lead as main cast in the movie. They also allow viewers to quickly identify with them. The linguistic emblem, 'Desamour Company LTd presents' projects reliability to the message in the advertisement poster.

Poster 5

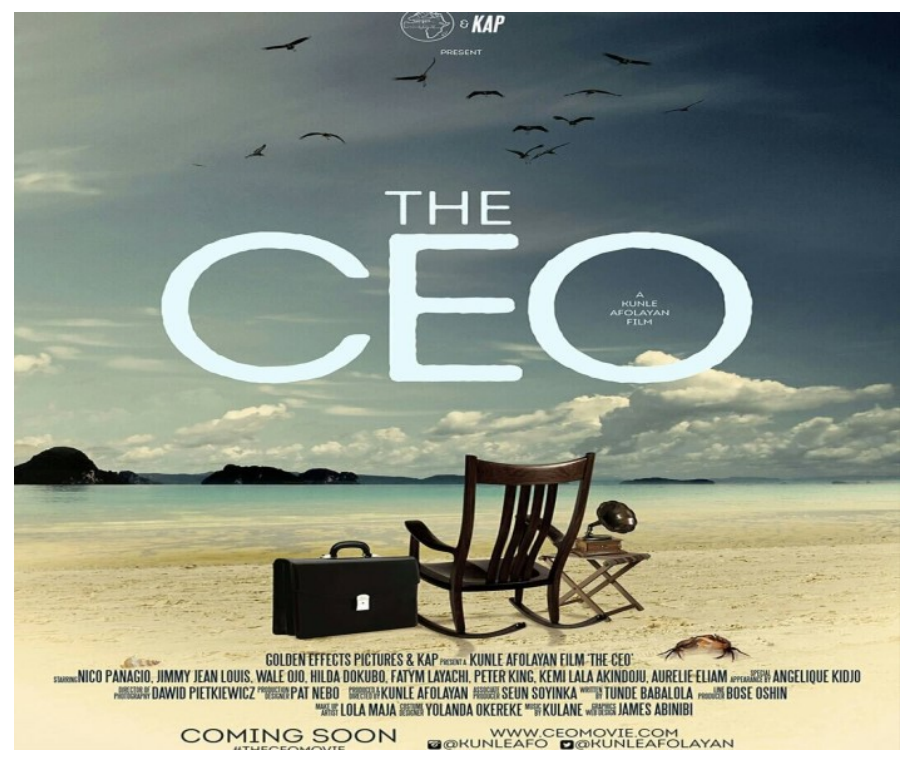

Figure 5. The $C E O$ film poster 
The film the poster above advertises is a thriller and was produced in 2016 by Kunle Afolayan. The image producer of the poster deploys inanimate objects as the locus of attention in order to attract the audience to the poster. The objects include a briefcase, an empty rocking chair, a stool and gramophone, which are all placed on a sandy beach. Other parts of the lead or comp.LoA are the integration of the landscape and its living elements, which comprise: the birds in the sky, the clouds, hills, sea, the crabs and sea shell placed on both sides of the chair. They make the background true to reality and they inform viewers that the film setting is that of a beach.

The displays of the leads are implicitly incongruent, in the sense that the image of the chair and its complements are the symbols of the displayed product/ PA/ film title. Hence, the empty chair signifies and confers the authority/seat of power, comfort and sense of relaxation of a Chief Executive Officer (CEO) or a highest-ranking person in an organization. A visual emblem is placed beside the verbal word, 'KAP' at the top of the poster and this implies that it one of the movie's production companies.

The linguistic components of the datum consist of the PA made salient in large fonts and centralized in the visual field in white colour, which accentuates it from other semiotic modes. In addition, The SA is inscribed as 'A kunle Afolayan film' in smaller prints integrated in the letter ' $\mathrm{O}$ '. This framing indicates that the PA and SA are related meaning-making modes that provide independent and complementary information. The SA relates to viewers that the film is owned and directed by the named person. This gears viewers' interests who are aware of his acting and directing prowess that indeed the film narrative and cinematography will be a promising one. Similarly, the enhancer is forgrounded at the bottom of the poster containing the cast and crew members. Below it is the tag, 'Coming soon', which is to further arouse viewers' anticipation in patronizing the movie.

\section{Poster 6}

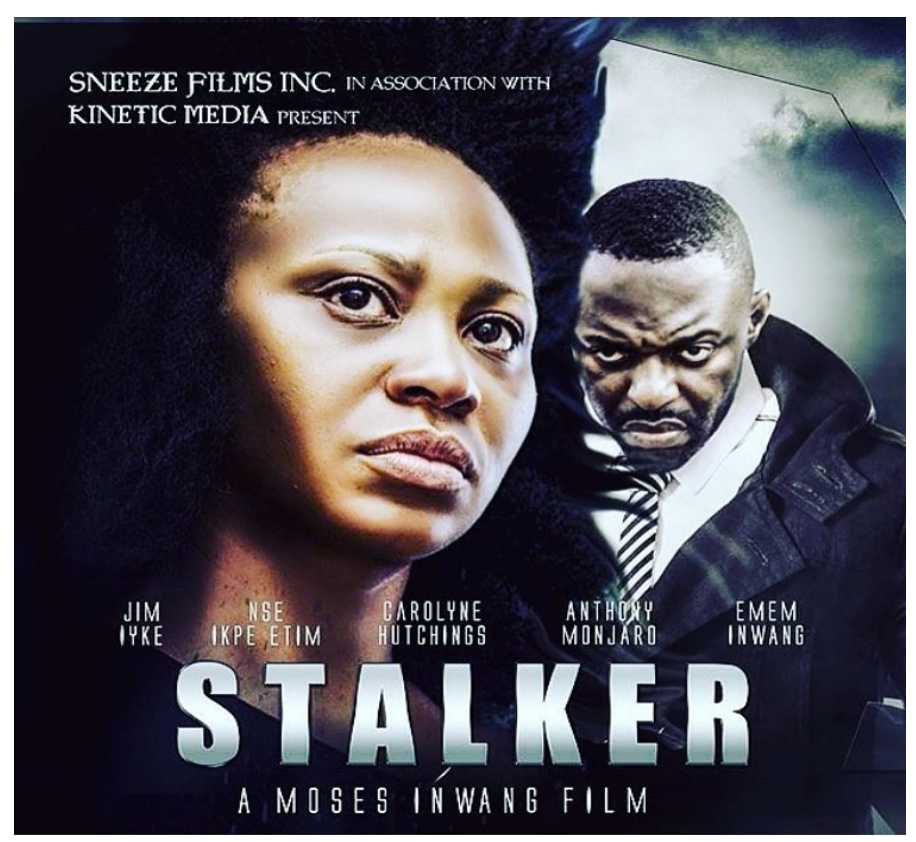

Figure 6. Stalker film poster 
'Stalker' is a thriller movie produced in 2016 by Moses Inwang and Caroline Danjuma. The leads in the poster convey centrality in the visual composition. They are the central signified that draws viewers to the locution in the image and are represented by a man and a woman. The woman is placed on the left hand side of the poster while slightly tilted to the right. Her image occupies more than half of the poster space. She also maintains an eye-view camera angle with her gaze upwards away from viewers as though she is focused on something the viewers cannot identify. The face and facial features and neck of the female lead are salient to make her an object of viewers' interest. Her hair appears to be undone which could be because of her long and uncertain facial expression. The information value of the female lead guides the viewers to the male represented participant on the right who is dressed in cooperate outfit. He emerges as a dangerous, determined and fearless person and appears to be in transit towards achieving an aim or get his prey that is obviously the female lead, hence, her facial expression. The frontal positioning of the male lead is to vividly depict him as the villain or the 'stalker' in the movie plot. Hence, he is visually symbolized as the thematic focus of the film, which strengthens the persuasive force intended by the image designer.

The linguistic modes of the PA /'stalker', SA / 'A moses inwang film' and tags / names of the visually represented cast are to lend credence to the meaning communicated via the visual modes. In addition, the linguistic emblems, 'sneeze film inc. and kinetic media' are used to give authenticity to the advertisement poster. The predominant colour in the poster is black to indicate the seriousness of the movie narrative. Black hue is evident in most part of the background as it can be portrayed in the hairs of the leads, the cloths of the female lead and major parts of the male lead's attire. The female lead is depicted in black colour to imply that she is deeply rooted in fear and misery. Also, there is a blend of black and white colours, which creates a poorly lit reflection above the male lead and symbolizes the gloomy world he resides. However, the linguistic elements are imprinted in white colours to accentuate them against the dark background and project them as separate semiotic entities.

\section{Call -and-visit information in the Advertisement Posters}

The world has become a global village where social networks are recent trends utilized by advertisers to reach out to the audience irrespective of the differences in age, gender and other social parameters characterizing them. Nollywood film poster designers sometimes employ a multi layered advertising strategy by the tactically inscribing social media handles on film posters to direct prospective audience to source for more information through some available social networks. The $C E O$ movie poster contains Instagram, Twitter and official websites of the films and movie producers to inform viewers that, available information is provided in the listed social media handles. The social media icons are to further enhance the information provided by their linguistic counterparts.

Other aspects of call-and-visit information mostly occupies the bottom of the poster advertisements and contain information on the date and where the films advertised will be available for viewing by prospective viewers. This is evident in 'Omugwo' and 'Up North' posters where the texts, 'Cinemas April 7' and 'in cinemas December 28' both inform viewers on date and venue of the viewing of the films.

\section{Visual-Verbal Ideational Intersemiotic Relations in the Advertisement Posters.}

The visual modes coordinate and complement the verbal semiotic resources to express the integration of the meaning bearing potentials of the film advertisement posters. Repetition is used in the advertisement posters to emphasize the significance of the ideas conveyed in the advertisements. 
This is evident in figure 3: Up North, where the primary announcement, 'Up North' is inscribed in the image of the arrow pointing towards the North and the upward gaze of the lead reiterated in the word preposition in the PA/'Up'. Similarly, in figure 2, Tiwa's Baggage, visual-verbal reiteration is realised through the word baggage/ PA and the visual image of the baggage. Also the word, 'Tiwa's' in the PA is repeated in a partly shown or subjective representation of the carrier of the baggage as being her possession which connotes a burden or negativity experienced by her. In figure 4: Ghana must go, the PA/ title correspond with the image of the Ghana must go sack bag before one of the leads, Nkem Owoh. The sack bag is also visually reiterated at both ends of the PA as quotation marks. Repetition is also evident in figure. 6: stalker as the verbal text/ PA repeats directly the image of the male lead in the visual composition.

Synonymous relationships are employed in the advertisement posters to communicate effectively the themes of the advertisements. Synonymous relationship is observed in Figure. 1: Omugwo where the PA or film title relates to the traditional Igbo dressing of the elderly lead. In figure 4: Ghana must go, the visually projected flags relates to the countries: Ghana and Nigeria respectively as national symbols of these countries, so is the images of Kofi Adjorolo dressed in Kente and Nkem Owoh in traditional Igbo attire. In addition, the tags representing the names of each of the cast have semantic proposition to the image of the leads. So is it in figure 5: The CEO. In addition, in The CEO, the PA relates with the image of the chair. It connotes the seat of a CEO.

Meronymy relation is evident figure 5, the CEO as the pictorials of various tools such as empty chair, suitcase, etc. are veritable tools used by a CEO.

The tool of collocation is employed by the producers of the image to support the centrality of the posters. Collocation is used in figure 1: Omugwo where the visualised babies/Comp. LoA and the PA/ 'Omugwo' are collocates because when the lexical word, 'Omugwo' is mentioned, the symbolism of a baby comes to mind, as babies are the main course of Omugwo activities. In figure 3: Up North, the Comp.LoA or the image of the luggages in the poster are collocates to the new corp member heading to the North to serve the nation.

\section{The Use of Graphological Features in the Advertisement Posters}

Graphology is a purely linguistic term and one of the levels of linguistic analysis. However, scholars such as Kress and van Leeuwen (2006), van Leuween (2005) have made efforts, and van Leuween and Jewitt (2001) to incorporate graphological features in the study of multimodality as verbal semiotic resources are one of the different modes important in visual communication. Graphological features are based on lexical properties such as spellings, punctuation, typography, etc. when these graphological forms are violated, implied meanings are generated. In visual communication, image producers manipulate these grammatical features to communicate their intended meanings to the target audience or viewers. The graphological features characterizing the primary announcement or centrality of the movie posters are considered for analysis.

The use of upper case lettering are predominantly employed in the advertisement posters to lay emphasis to the semantics of the word and bring to fore to the viewers, the locution of the image. In figure 3: Up North, the verbal anchorage is written in capital letters and placed like an arrow pointing towards the supposed Northern direction. Similarly, in figure 6: stalker, the lexical word, 'Stalker' is also imprinted in upper case to perform the role of centrality. It helps focus viewers' attention to that particular section since it is not centralized. Also, in figure 2 : Tiwa's baggage, the lettering 'Tiwa's baggage' infused in yellow colour is similar in design to the image of the baggage to reiterate 
the significance of the idea. This is similar to figure 1: Omugwo, figure. 3: Up North, figure. 4: Ghana must go, and figure 5: The CEO. The primary announcements in these poster images are imprinted in upper case and bolded in white, black and orange colours to emphasize that the film poster advertisements centers on the various themes thereby increasing the films recall.

\section{Findings}

The study reveals that visual semiotic resources are heavily grounded in the posters than the linguistic modes and the potency of the visual modes overwhelms its linguistic counterparts. However, the co-deployment of both the visual and linguistic resources such as gaze, lettering, posture, colour, angle, social distance, icons, etc. are significant in communicating the intended inter semiotic meanings of the advertisers to the perception of the viewers and in turn convince them to patronize the movie advertised.

Kress (2010, p.79) maintains that a semiotic mode is a socially and culturally shaped resource for meaning making. In consonance, Kress and van Leeuwen (2006, p.35) posit that semiotic modes are shaped by both the intrinsic characteristics and potentialities of the medium and by the requirements, histories and values of societies and their cultures. This is true of most of the poster advertisements. In communicating persuasive meanings, the semiotic resources draw attention to peculiar cultural, political and social issues in the Nigerian environment. The semiotic resources in Tiwa's baggage, Up North, Ghana must go and Omugwo advertisement posters exhibit peculiar cultural specific meanings. In Omugwo, the knowledge of the Nigerian context affords viewers lucid interpretation of the meaning communicated in the poster. Also, in Ghana must go, there is a mutual contextual interpretation of the meaning communicated by the modes. Similarly, in Tiwa's baggage, the lettering / name 'Tiwa' is peculiar to the people of south Western Nigeria, thereby, depicting the film as Nigerianised / acculturated.

The findings from the study reiterates in existing literatures, the significance of colour in visual communication. Colour has not only been used for aesthetic purposes to appeal to the emotions of the viewers but it has been employed ideationally in the advertisements to symbolise people, places, things and ideas. The meanings communicated are sometimes specific and paramount to the Nigerian socio cultural milieu. This finding is canonical with Afolabi (2011, p. 52) submission that "colours are the building blocks of visual communication because they have symbolic meanings associated with them which could depend on the culture and daily experience of the target audience". Also, colour performs textual roles in advertisement posters to create coherence and framing between and among various semiotic modes embedded in the advertisements.

Yuen (2004) admits that Lead and Emblem are the only obligatory elements in printed advertisements, the analysis of the advertisement posters reveals contrary, as announcement/film title is also an obligatory element. The linguistic texts/announcements in the posters are the verbal anchorages that signal the thematic preoccupation of the film advertised and draws viewers to the locution and other meaning-making parameters communicated in the posters. Also, the displays of most of the images in the posters are congruent as they represent the thematic focus of the film advertised. This is employed to further strengthen visual-verbal relationship in the conveyance of meaning.

The majority of the advertisement posters do not contain taglines/secondary announcement. Hence, the verbal resources give less information while more information is provided by the visual modes to arouse viewers' curiosity to see the movie advertised. This finding supports the heavy 
reliance of visual resources by the image producers in the encoding of messages in visual communication.

\section{Conclusion}

The findings from the study have demonstrated that visual modes are dominant and primary in the meaning making process of Nollywood advertisement posters. Due to the tendency of visual modes to be easily read than linguistic modes, Nollywood image producers preponderantly employ them as major persuasive and communicative strategies to captivate the audience. However, the synergy of both linguistic and visual multimodal resources or modes of signification result in the expansion of meaning in the film advertisement posters. These visual and linguistic semiotic resources are skillfully encoded to actualize the intended goals of the image designers/ advertisers. The advertisers are aware of the immediate context of the prospective viewers. Hence, they use it as a driving force in manipulating the audience to achieve their intended goals. The shared knowledge of the advertisers and the prospective viewers in relation to the Nigerian socio cultural context assist in the processes of meaning making and meaning-comprehension in Nollywood advertisement posters.

\section{References}

[1] Afolabi, A. (2011). Graphic communication in Nigeria. Lagos, Nigeria: Pioneer Publishing.

[2] Afolayan, K. (Director). (2016). The CEO (Film poster) . Golden effects.http://en.m.wikipedia.org/wiki/The_CEO

[3] Afolayan, K. (Director). (2017). Omugwo (Film poster). Golden effects. https:/flixanda.com/movie/42/omugwo

[4] Arase, F. R. (Director). (2016). Ghana must go (Film poster). Desamour Company. https://www.google.com/amp/s/www.pulse.ng/entertainment/movies/pulse-moviereview-ghana-must-go-is-a-well-made-movie-with-often-very-funnyscenes/52sq5pq.amp

[5] Ertugrul, A. M. and Karagoz, P. (2018). Movie genre classification from plot summaries using bidirectional LSTM. In proceedings of IEE $12^{\text {th }}$ International conference on semantic Computing . (ICSC 2018) 248251.

[6] Halliday, M. A. K. (1978). Language as social semiotic. London: Edward Arnold.

[7] Halliday, M. A. K. (1985). An introduction to functional grammar. London: Edward Arnold.

[8] Inwang, M. (Director). (2016). Stalker (Film poster). Sneeze films, Kinetic media. https:// steemkr.com//Nigeria/@omodara/things-you-did-not-know-about-nigeria

[9] Kress, G. \& van Leeuwen, T. (2002). Colour as semiotic mode: notes for a grammar of colour. Visual communication. 1(3), 343-369.

[10] Kress, G. \& van Leeuwen, T. (2006). Reading images: The grammar of visual design. ( $2^{\text {nd }}$ ed.). London/NY: Routledge.

[11] Kress, G. (2010). Multimodality: A social semiotic approach to contemporary communication. New York Routledge.

[12] Kress, G. Leite-Garcia R. \& van Leeuwen, T. (1997). Discourse semiotics. In van Dijk, T. (ed.) Discourse as structure and process. London: Sage.

[13] Lemke, J. L. (1995). Textual politics discourse and social dynamics. London and Bristol: Taylor and Francis Ltd.

[14] Liu, J. (2013). Visual images interpretive strategies in multimodal texts. Journal of language teaching and research, 4(6), 1259-1263.

[15] Martinec, R. (1996). Rythym in multimodal texts. London: The London institute.

[16] O' Toole, M. (1994). The language of displayed art. London: Leicester University Press. 
[17] O’Halloran, K. L. (2008). Systemic functional multimodal discourse analysis (SF-MDA): Constructing ideational meaning using language and visual imagery. Visual Communication, 7(4), 443-475.

[18] Olateju, M. \& Oyebode, O. (2014). Introducing multimodality. Ibadan: College Press and Publishers.

[19] Oshin, T. (Director). (2018). Up North (Film poster). Ankale Films, Inkblot productions.https://m.imdb.com/title/tt8631800/

[20] Ron, S., \& Phillip, L. (2004). Discourse and technology. multimodal discourse analysis. Washington: University Press.

[21] Royce, T. (1998). Synergy on the page: Exploring inter-semiotic complementary in page-based Multimodal text. JASFL occasional papers 1, (1) 25-49.

[22] Stephen, B. (Director). (2017). Tiwa's Baggage (Film poster). ShutterSpeed projects.https://www.google.com/amp/s/nollywoodobserver.wordpress.com/2017/05/22/ movie-review-tiwas-baggage/amp/

[23] Van Leeuwen, T. (1999). Speech, music, sound. London: Macmillan.

[24] Yuen, C.Y. (2004.) The construction of ideational meaning in print advertisements. In: O'Halloran, K. (Ed.), Multimodal discourse analysis: Systemic-functional perspectives. (pp. 163-195). London: Continuum. 